
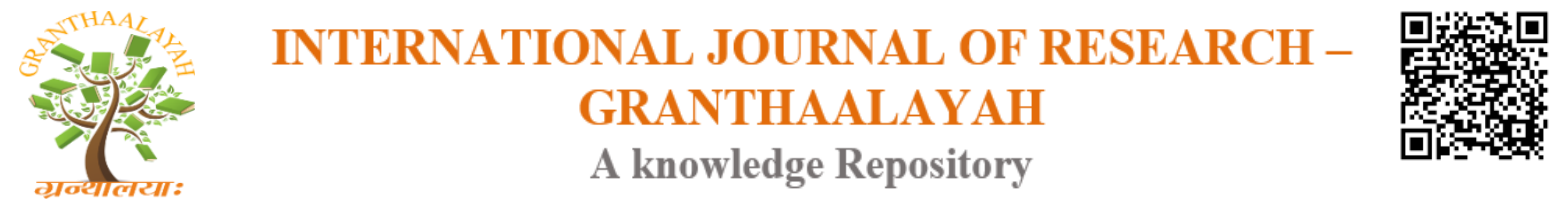

Management

\title{
THE IMPACT OF SOCIAL-MEDIA PERFORMANCE ON SALES OF RETAIL-FOOD BRANDS
}

\author{
Qingqing Chang ${ }^{1}$, Yuqi Peng ${ }^{2}$, Paul D. Berger ${ }^{3}$ \\ 1,2,3 Bentley University Waltham, MA 02452, U.S.A.
}

\begin{abstract}
This paper considers the relationship between various social-media activities of a company/brand and its sales. We use quarterly revenue data of 13 retail-food brands, over 4 quarters, as our dependent variable. We use 6 independent variables involving the social-media activity of these companies on Twitter, YouTube, and Instagram. We use descriptive statistics to describe our data, and use simple, multiple, and stepwise regression to perform our analyses. We find that certain social-media activities do, indeed, positively relate to quarterly sales revenue.
\end{abstract}

Keywords: Social-Media; Twitter; YouTube; Instagram; Retail-Food Industry; Multiple Regression; Stepwise Regression.

Cite This Article: Qingqing Chang, Yuqi Peng, and Paul D. Berger. (2018). "THE IMPACT OF SOCIAL-MEDIA PERFORMANCE ON SALES OF RETAIL-FOOD BRANDS.” International Journal of Research - Granthaalayah, 6(2), 1-12. https://doi.org/10.5281/zenodo.1185601.

\section{Introduction}

Nowadays, social media is playing a more and more important role in people's daily life; it has become one of the media that people use most frequently. As a result, more and more businesses have realized the importance of social media marketing. In order to win a position in today's market, no company can afford to fall behind in this social-media war. Thus, we can see that many companies are trying hard to be active in large social-media platforms, such as Twitter, YouTube, Facebook and Instagram (e.g., DeMers, 2014). Retail-food brands are great examples. These brands update videos, tweets, and pictures every day, hoping to be more exposed to customers, so that they can achieve superior sales performance (Jackson, 2016). They believe that utilizing social media as a promotional and collaborative tool can successfully build a relationship with their customers by enhancing the level of communication, increasing brand awareness, and stimulating their consumers to actually purchase their products.

However, is that really the case? Is it true that the more active the companies are in social-media platforms, the better their sales performance? Is there any possibility that their efforts in social media platforms provide no sales benefit? 
In order to consider this question, we examined this topic to see if there is actually a relationship between companies' social-media activity and their sales performance. In this paper, we selected three social-media platforms - Twitter YouTube and Instagram and considered 13 brands in the retail-food industry as examples. These brands include McDonald's, Duckin' Donuts, Starbucks, Chipotle, Wendy's, Shake Shack, Pizza Hut, Taco Bell, Tim Horton, Burger King, Jack-In-TheBox, Sonic-Drive In, and Domino's. Specifically, we took a quarter (3 months) as a period, and collected brands' quarterly data of Twitter, YouTube and Instagram activity - including the number of tweets, number of Twitter followers, YouTube video-view ranks, YouTube subscribers, Instagram followers, and Instagram posts, as well as quarterly revenue data from the brands' financial statement. The goal was to study whether the social-media activity was related to the sales revenue.

\section{Literature Review}

\subsection{Social-Media Influence in Different Industries}

There are many people who have concluded that social-media platform activity can improve brands' sales, at least theoretically. Hou (2016) studied the application of social media in enterprise marketing. Her article analyzed the characteristics, advantages and practical values of enterprise social-media marketing and concluded that social-media platforms can help companies to get more attention from customers and potentially improve sales performance. However, she did not provide/use any data to illustrate the relationship.

Martin (2017) published a book related to social-media marketing the author concluded that companies' activities on social-media platforms can help to build brand image quickly and efficiently. Nevertheless, she also did not provide any supporting data analysis.

Other scholars have collected data and performed analysis to examine the degree of influence that social-media activity would bring to certain industries. Doa, Koa, and Woodside (2014) studied the effects of a brand's sports sponsorship in social media on the brand's consumer's congruity and brand-relationship quality. They conducted a survey on this topic, gathered data from 322 respondents, and found that a brand's sports sponsorship in social-media activities relating to sports brands had a significant effect on a brand's consumer's congruity and that this congruity significantly influences the brand's relationship quality. However, they collected only subjective data from respondents and did not collect objective data from social media.

Kumar, Bezawada, Rishika, Janakiraman, and Kannan (2016) studied the effects of firmgenerated content (FGC) in social media on customer behavior. Through surveys, they assembled a data set composed of customers' social-media participation data, transaction data, and attitudinal data. They found that various components of FGC had a positive impact on customer behavior; the effect of FGC receptivity was the largest effect.

Kim, Park, and Park (2013) examined the impact of online word of mouth (WOM) and expert reviews on movies' box office revenues. They used a sample of 169 movies released in 2008; the study discovered that the frequency of online WOM and the valence rating of expert reviews were significant factors for box office outcomes in the domestic market. The study also found 
that only the frequency of online WOM was a significant factor in the international markets. However, the study used data from film-related online media such as Box Office Mojo and IMBD and did not analyze the WOM data from other social-media data sources.

Istanbulluoglu (2017) studied the impact of multiple response times on consumer satisfaction. He used data from Facebook and Twitter. His analysis revealed that a speedy response increases satisfaction, regardless of the consumers' objectives.

Rodriguez, Ajjan and Peterson (2014) studied the impact of customer relationship management (CRM)/Social-Media Technology on the customer-orientation process and organizational sales performance and concluded that CRM and social-media technology positively influence customer orientation activities, which in turn, positively impact sales performance. However, in the study, they collected only subjective data from respondents and did not collect objective data from social media; there is no measurement of the activity of different brands involved in the study.

\subsection{Social Media Influence in Food-Retail Industry}

When it comes to the retail-food industry, large numbers of companies have heavily invested in social media and have expanded their social recognition and have enjoyed increasing sales revenues due to this revolution.

Starbucks is a worldwide traditional brand with a long history since 1971, known for lots of things: great coffee, friendly baristas and what seems like a near-complete takeover of practically every street corner in America. However, it's also the most successful example of the retail-food industry overwhelmingly benefiting from investment in social media.

Huff (2014) discussed Starbucks investment in social media. He said that Starbucks' socialmedia team is great at offering customer service of local coffee shops on a grand scale over its social-media channels. Although Starbucks is a huge company, customers can still get individual attention on social media. What's more, he noted that one of the reasons behind Starbucks' social-media success is that drinking coffee is a social activity. People love to meet over coffee, bring each other coffee, swap stories about coffee, and build coffee acquisition into their morning routines. By extension, sharing the coffee-drinking experience is a natural fit for platforms like Twitter and Facebook. Starbucks posts unique content on Twitter and also uses Twitter as a service to reach out to customers, talking about their in-store and product experiences. All tweets are directed at specific Twitter users who have spoken to Starbucks in their own timeline - sometimes with a complaint or negative feedback. Figure 1 illustrates some examples on personalized responses by Starbucks. 
Starbucks Coffee @Starbucks.9h

Replying to @moniicaxo

Because we like seeing you all the time, Monica!

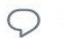

Starbucks Coffee @ @Starbucks·9h

Replying to@mschantillyatx

To order one now, all you have to do is tap on iOS: sbux.co/peppermint - or on Android: sbux.co/peppymo. As simple as that! $\theta \sigma$

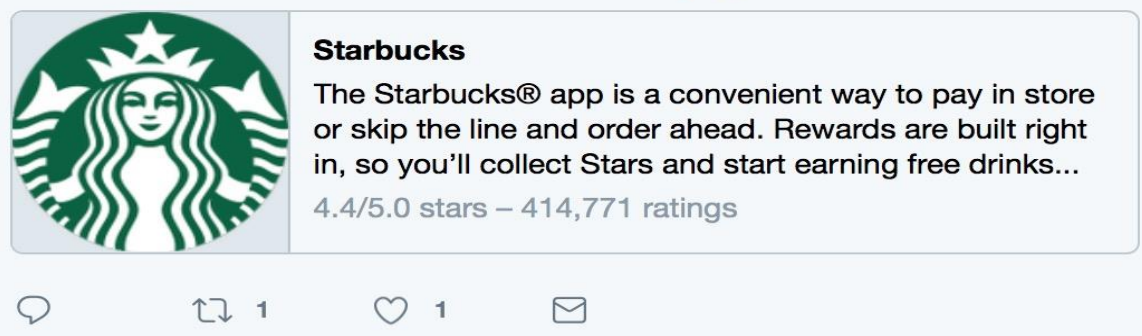

Figure 1: Examples of Starbucks' personalized responses

According to Dua's research on Shake Shack (2015), Shake Shack does essentially no traditional marketing, but has a strong presence on social media, which speaks to its relevance among Millennials. We can see from the report of Goldman Sachs; the presence of Shake Shack is massive relative to even social-media heavyweights such as Taco Bell. In terms of pure numbers, Shake Shack does not have the largest following on most of these social platforms, and its advertising budget is also tiny. However, it has the biggest audience for its size, because it has only 40 stores nationally, compared to the thousands of retail outlets that both McDonald's and Taco Bell, for instance, have. Dua suggested that Shake Shack's social- media prowess has clearly contributed to the brand's overall success.

Mary Keelty, CMO at digital marketing agency PM Digital, argues that, “...it is the level of dedication to understanding their [Shake Shack's] core audience, and speaking to them in a native fashion, that has resulted in such success." Figure 2, shows the relative situation of Shake Shack for Vine follows and Instagram followers.
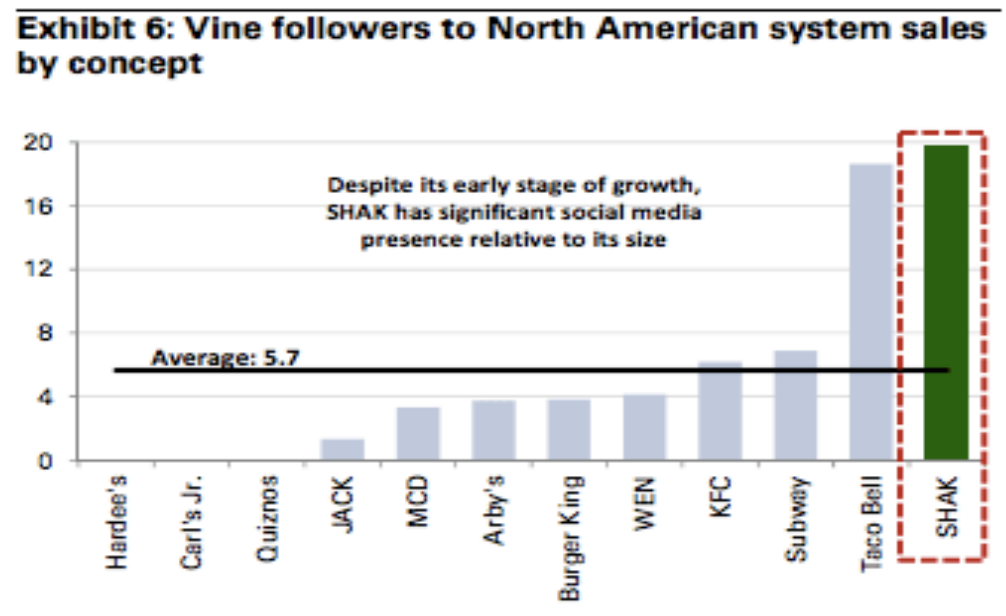

Source: Vine, Goldiman Sachs Glabal Investment Research 


\section{Exhibit 7: Instagram followers to North American system sales by concept}

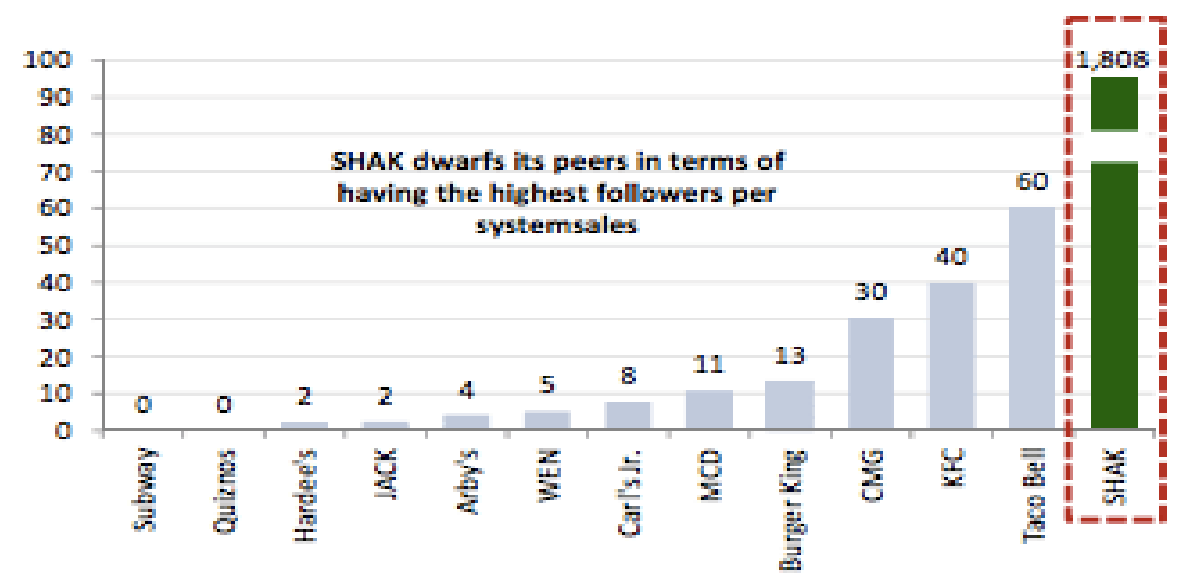

Source: Instagram, Goldman Sachs Global Investment Research

Figure 2: Shake Shack followers on Vine and Instagram

\section{Methodology}

\subsection{Data and Data Sources}

We obtained our revenue data from the recent quarterly reports (2016Q4, 2017Q1, 2017Q2 and 2017Q3) that companies uploaded to their official website. (Due to availability, for Jack-In-TheBox and Sonic-Drive In, we collected only 2 and 3 quarters of data, respectively, for a total of 49 $[11 * 4+2+3]$ data points. In addition, in terms of data on social- media participation, we collected monthly data from socialblade.com, a website that focuses on social-media data, combining the data by quarter, to be consistent with the time periods of the revenue data. We used the following data: (1) the number of tweets published in a quarter, (2) the change in the number of Twitter followers during a quarter, (3) the change in the number of YouTube subscribers during a quarter, (4) the number of Instagram posts in a quarter, and (5) the change in the number of Instagram followers in a quarter. We also used (6) the YouTube video-view rank in the quarter. To sum up, we collected data on 6 independent variables in the retail-food industry from Twitter, YouTube, and Instagram and assembled each independent variable by quarter. We have the dependent variable of the company's quarterly revenue data. All of the independent variables are in ratio-scale form, except for YouTube video-view rank. We recoded this variable as follows, into what we view as an interval-scale variable:

\begin{tabular}{|l|l|}
\hline Original YouTube video-view rank: & Score after recoding \\
\hline $1-50000$ th & 5 \\
\hline $50001-100000$ th & 4 \\
\hline $100001-150000$ th & 3 \\
\hline $150001-200000$ th & 2 \\
\hline After 200001th & 1 \\
\hline
\end{tabular}




\subsection{Hypothesis}

We postulate the following hypotheses, based on the literature and some "common sense." All relationships are referring to a linear relationship -

H1: The number of tweets the brand publishes in a quarter has a positive relationship with the brand's quarterly sales revenue.

$\mathrm{H}$ 2: The change in the number of twitter followers of a brand in a quarter has a positive relationship with the brand's quarterly sales revenue.

H3: The change in the number of YouTube subscribers of a brand in a quarter has a positive relationship with the brand's quarterly sales revenue.

H4: The YouTube video-view rank (after recoding) during the quarter has a positive relationship with the brand's quarterly sales revenue.

H5: The number of Instagram posts a brand updates in a quarter has a positive relationship with the brand's quarterly sales revenue.

H6: The change in the number of Instagram followers of a brand in a quarter has a positive relationship with the brand's quarterly sales revenue.

In summary, based on previous literature, we have hypothesized that all the independent variables (including YouTube video-view rank score after recoding) have a positive relationship with the dependent variable. In other words, more tweets and Instagram posts the company published in a quarter, the higher the brand/company's sales performance in a quarter would be. Moreover, a larger increase in a quarter on Twitter and Instagram followers and a larger increase in a quarter in YouTube subscribers would also have a positive relationship with the brand/company's revenue in the quarter. In addition, the higher the score of recoded YouTube video-view rank, the more the brand/company's sales revenue would be.

\section{Analysis and Discussion of Results}

\subsection{Descriptive Statistics}

As we noted, in our investigation, there are 49 rows of data (i.e., data points). The average quarterly sales revenue of the retail-food brands is 1306.4 million USD. Indeed, all revenue values are in USD. The minimum of sales revenue of one quarter is 73.3 million, that of Shake Shack, in the first quarter of the 4 quarters studied ( $4^{\text {th }}$ quarter of 2016), whereas the maximum is 6049.7 million, which appears in the third quarter studies $\left(2^{\text {nd }}\right.$ quarter of 2017) for McDonald's. The standard deviation of the 49 values is 1999.0 , which indicates somewhat large differences in sales revenues across the 13 brands/companies and 4 quarters.

In terms of Twitter followers of different retail-food restaurants, on average, a restaurant has approximately 43.5 thousand followers gained per quarter, whereas the number of tweets each quarter increased about 11.7 thousand.

When it comes to YouTube, which is a video-oriented social medium, on average, there are around 4.6 thousand subscriptions on each restaurant's pages of each quarter. 
Among the Instagram pages of the sample data, the average increase is about 139.9 thousand each quarter for each restaurant while the average increase in the number of posts is around 0.06 thousand on each company's page of each quarter.

\subsection{Test of Hypotheses}

Firstly, we would like to know which independent variables are related to the dependent variable, so we began by running a multiple regression. We obtained the following results shown in Figure 3.

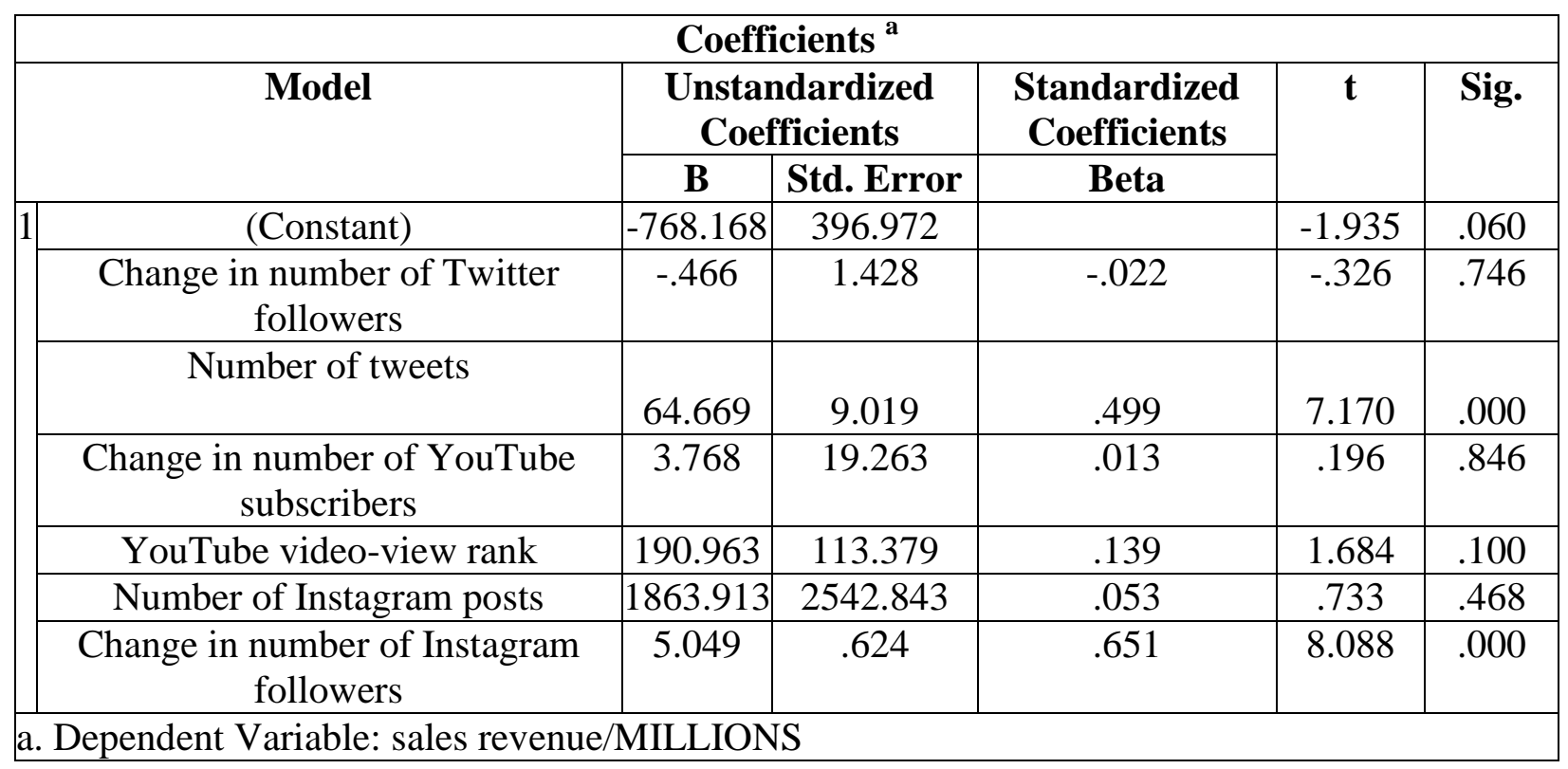

Figure 3: Coefficients table for multiple regression analysis

From Figure 3, we can see that the four independent variables: change in number of Twitter followers per quarter, change in number of YouTube subscriber per quarter, YouTube videoview rank, and number of Instagram posts per quarter, have a significance (p-value) above 0.05, which means that they are either irrelevant to a brands' sales performance, or redundant with the two significant variables ( $p<.05$; indeed, in both cases, $p=.000$ to three digits): number of tweets in the quarter and change in the number of Instagram follows in the quarter, or, possibly, redundant with each other. So, we can say so far that the two significant independent variables each give us incremental predictive value about a brand's quarterly sales revenue. In addition, we can see that they both have a positive coefficient, and thus, are both positive predictors of brands' quarterly sales revenue.

In order to determine the irrelevancy vs. redundancy status of the aforementioned four nonsignificant independent variables: change in number of twitter followers per quarter ( $\Delta$ Twitter), change in number of YouTube subscribers per quarter ( $\Delta$ YouTube), number of Instagram posts per quarter (N-Ins. Posts) and YouTube video-view rank (YouTube VVR), we ran simple regression with each of them and quarterly sales revenue. 
For the first three of these variables, the p-value is above .05 , indicating that at the .05 significance level, they are not significant, essentially indicating that they are irrelevant to quarterly sales revenue. Specifically, the p-values for these simple regressions are as follows:

\begin{tabular}{|c|c|}
\hline Variable & p-value \\
\hline$\Delta$ Twitter & .955 \\
\hline$\Delta$ YouTube & .186 \\
\hline N-Ins. Posts & .358 \\
\hline
\end{tabular}

However, a simple regression between quarterly sales revenue and YouTube video-view rank (YouTube VVR) reveals a p-value of .000, indicating that it IS relevant to quarterly sales revenue, and thus, in the multiple regression, redundant with other variables in the equation/model. The value of R-square is .330. Also, its coefficient is positive.

Given the previous results, we finalized our analysis with a stepwise regression with quarterly sales revenue as the dependent variable and the 6 independent variables eligible to enter the stepwise regression. At this point, we were confident that the final stepwise regression model would include either the two variables that were significant in the original multiple regression, OR, would include those two variables and YouTube VVR as a $3^{\text {rd }}$ variable. As we can see in Figure 4, the model summary, the final stepwise regression model includes only the two originally significant variables - thus indicating that YouTube VVR is redundant to these two variables, change in the number of Instagram followers and number of tweets.

\begin{tabular}{|l|c|c|c|c|}
\hline \multicolumn{4}{|c|}{ Model Summary } \\
\hline Model & R & R Square & Adjusted R SquareStd. Error of the Estimate \\
\hline 1 & $.742^{\mathrm{a}}$ & .551 & .541 & 1353.620 \\
\hline 2 & $.900^{\mathrm{b}}$ & .810 & .801 & 891.125 \\
\hline \multicolumn{2}{|c|}{ a. Predictors: (Constant), $\Delta$ Instagram followers } \\
\hline
\end{tabular}

Figure 4: Model summary of stepwise regression

Figure 5, the coefficients table, gives us the specific equation of the final model.

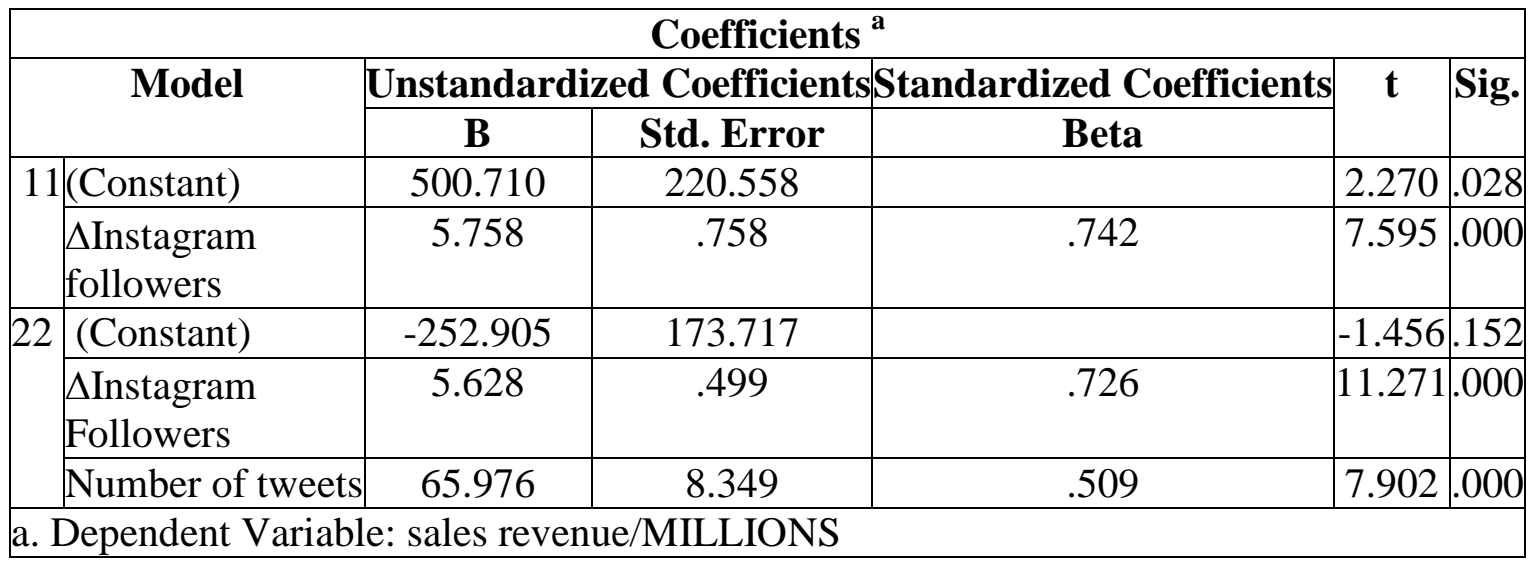

Figure 5: Coefficients table for stepwise regression 
We can predict the quarterly sales revenue of a retail-food company (Y) by the formula:

Y-predicted $=-252.9+5.628 *(\Delta$ Instagram followers $)+65.976 *($ Number of tweets $)$

In essence, $\mathrm{H} 1, \mathrm{H} 4$, and $\mathrm{H} 6$ were confirmed, although the stepwise regression did not include "YouTube VVR" due to redundancy. H2, H3, and H5 were not confirmed.

\section{Discussion}

From the results, we can reach various conclusions about the impact of the independent variables on a brand's sales revenue.

- From the multiple regression analysis, assuming other variables in the model are held constant, if a brand posts more tweets on its Twitter pages, the higher its sales revenue will be. This can be explained by the fact that the more tweets that are posted, the more information followers will get about the products or the events, and then it is likely that more people will come to the restaurant.

- From the multiple regression analysis, assuming other variables in the model are held constant, if a brand has gained more followers on its Instagram in a quarter, the more sales revenue they will get in that quarter. This can be explained by the fact that people who follow the brand's Instagram pages show interest in the brand and they are more likely to choose that restaurant when they dine out. Furthermore, when the brand updates its Instagram page with a new post featuring their new event, if it has more followers, then more people will know about the event and there will be more people likely to attend the event.

- From the simple regression analysis, if a video-view rank of a brand on YouTube is higher in one certain quarter, the sales revenue of this brand will be higher. This can be explained by the fact that a higher rank means that the brand enjoys more popularity in the market among consumers. Moreover, it means that more consumers are familiar with the brand, which, in turn, contributes to higher sales revenue. However, from the multiple and stepwise regression analyses, we note that this variable is redundant with number of tweets and the change in Instagram followers, and once knowing the values of the latter two variables, the variable does not add significant incremental predictive ability to a brand's sales revenue.

- From the multiple regression analysis, we do not have sufficient evidence to conclude that, assuming other variables in the model are held constant, a change in the number of twitter followers in a quarter is associated with a brand's sales revenue in that quarter. This might be explained by the fact that some brands would buy followers on Twitter to pretend to be popular in the market place, and to gain a higher rank-order.

- From the multiple regression analysis, we do not have sufficient evidence to conclude that, assuming other variables in the model are held constant, the number of posts on its Instagram page in a quarter is associated with a brand's sales revenue in that quarter. This might be explained by the fact that, sometimes, Instagram will hide some posts automatically, and followers will fail to notice some posts.

- From the multiple regression, we do not have sufficient evidence to conclude that, assuming other variables in the model are held constant, a change in the number of YouTube subscribers in one quarter is associated with a brand's sales revenue in that 
quarter. This might be explained by the fact that someone may subscribe the brand's page by accident. Second, the audience may not always check the pages that they have subscribed to earlier. Further, videos on the YouTube index page are related to the aspects that the customers have searched recently, but not necessarily what they have subscribed to.

\section{Limitations and Directions for Future Research}

We note some possible limitations of our study although we do not believe that they have substantially affected the results. Different retail-food companies were founded in different years. This may have lead to different degrees of time available to generate customer loyalty, which in turn, may have an influence on their earnings.

Target markets of different retail-food companies are different. For example, Chipotle typically targets millennials who prefer healthier fast food to hamburgers and French fries. And, there isn't a specific target market for McDonald's; they target almost everyone, as long as one wants to have their selected lunch and dinner dishes or is someone who is having a bite to eat or coffee in the morning (Moth, 2013; Jargon, 2016; Ashraf, 2017).

Also, we used data from the U.S. retail-food industry, and it is not clear whether the results are the same for the retail-food industry in other countries. Also, obviously, our results are appropriately interpreted only for the retail-food industry. Our results may or may not be true for various other industries.

When collecting data, we found that, often, one month in a quarter will have extremely higher or lower earnings than other months in the quarter. This variability from month to month indicates that our results could possibly change if we organized our data monthly or semi-annually, that is - using a time period other than quarters. This variability might be caused by changes of seasons, holidays and other reasons. For example, having no time to cook for themselves, students tend to go to fast-food restaurants more than often when they are in their final weeks of a semester, even if the restaurant doesn't post any tweets on twitter at that time. Of course, the choice of a time period of quarters was at least partially dictated by the format of available data.

The retail-food companies in our research are somewhat well-known to the entire United States; it is not clear whether our conclusions apply to local restaurants.

The sales revenue statistics we used in our research is the worldwide sales revenue of the restaurant. However, Twitter and YouTube is most widely used in North America. Customers in some other areas, such as China, have no or little access to these social media. However, the sales revenue of KFC in China is larger than that in the United States. Although we didn't look into this specific company (KFC), we cannot rule out the possibility that sales revenue of other restaurants we studied may be differentially influenced by KFC's and other restaurants' worldwide sales.

The YouTube video-view rank we used in our survey was the latest rank available when we conducted our survey. However, the sales revenues we used were, of course, changing over a 
quarter. However, in terms of the video-view rank, we looked up the previous ranks of these companies; there were no relative changes among the companies during the period of time we searched.

Future research can eliminate many of these limitations. One suggestion is to expand the sample size and try to include typical retail-food companies of different types. Another possibility for improvement is to take the influences of seasonality, holidays and other conditions into consideration to make the analysis more granulated. Finally, it would be useful to collect sales revenue data of some unlisted retail-food companies and the statistics of social media in other countries, such as Weibo in China and Naver in South Korea, as well as to expand the study to other industries.

\section{References}

[1] Ashraf, Sahial (2017), "McDonald's and the Rise of Disruption in Social Media Marketing, https://www.business2community.com/marketing/mcdonalds-rise-disruption-social-mediamarketing-01854400, June 1.

[2] DeMers, Jayson (2014), "The Top 10 Benefits Of Social Media Marketing," https://www.forbes.com/sites/jaysondemers/2014/08/11/the-top-10-benefits-of-social-mediamarketing/\#7ef5ca381f80, August 11.

[3] Do Hyunji, Ko, Eunju, and Woodside, Arch (2015), "Tiger Woods, Nike, and I are (Not) Best Friends: How Brand's Sports Sponsorship In Social-Media Impacts Brand Consumer's Congruity And Relationship Quality, International Journal of Advertising, 34(4), p. 658-677.

[4] Doga, Istanbulluoglu (2017), "Complaint Handling On Social Media: The Impact Of Multiple Response Times On Consumer Satisfaction," Computers in Human Behavior, V74, p72-82.

[5] Dua, Tanya (2015), "How Shake Shack Won Over Millennials, https://digiday.com/marketing/shake-shack-hit-among-millennials/, February 26.

[6] Hou, Jia (2016), “Application of Social Media in Enterprise Marketing." Jilin University Working Paper.

[7] Huff, Travis (2014), "How Starbucks Crushes It on Social Media https://www.socialmediatoday.com/content/how-starbucks-crushes-it-social-media, August 23.

[8] Jackson, Dominique (2016), "10 Standout Social Media Marketing Examples," https://sproutsocial.com/insights/social-media-marketing-examples/, December 28.

[9] Jargon, Julie (2016), "McDonald's Turns to Social Media to Draw Millennials," https://www.wsj.com/articles/mcdonalds-turns-to-social-media-to-draw-millennials-1476365404, October 13.

[10] Kim, Sang, Park, Namkee, and Park, Seung Hyun (2013), "Exploring the Effects of Online Word of Mouth and Expert Reviews on Theatrical Movies' Box Office Success," Journal of Media Economics, 26, p. 98-114.

[11] Kumar, Ashish, Bezawada, Ram, Rishika, Rishika, Janakiraman, Ramkumar and Kannan, P.K (2016), "From Social to Sale: The Effects of Firm-Generated Content in Social Media on Customer Behavior," Journal of Marketing, 80(1), p. 7-25.

[12] Martin, Gail (2017), "The Essential Social Media Marketing Handbook: A New Roadmap for Maximizing Your Brand, Influence, and Credibility," Career Press, Wayne, New Jersey.

[13] Moth, David (2013), "How McDonald's uses Facebook, Twitter, Pinterest and Google+,"

[14] https://econsultancy.com/blog/62329-how-mcdonald-s-uses-facebook-twitter-pinterest-andgoogle, March 13. 
[15] Rodriguez, M., Ajjan, H., Petersdon, R. (2014), “CRM/Social Media Technology: Impact on Consumer Orientation Process and Organizational Sales Performance," Journal of Marketing Development and Competitiveness, 8(1), p. 85-97.

[16] Walgrove, Amanda (2017), "5 Food \& Beverage Brands That Lead In Social Media Marketing, https://blog.sprinklr.com/food-and-beverage-brands-leading-in-social-media-marketing/, April 5 .

*Corresponding author.

E-mail address: pdberger1@ verizon.net 